\title{
Setting the Transgender Agenda: Intermedia Agenda-Setting in the Digital News Environment*
}

\author{
Thomas J Billard \\ Annenberg School for Communication \& Journalism, \\ University of Southern California \\ tbillard@usc.edu
}

October 9, 2018

\begin{abstract}
Transgender issues have recently emerged as highly salient topics of political contestation in the United States. This paper investigates one relevant factor in that ascent: intermedia agenda-setting between digital-native and legacy press news. Through a content analysis of the topfive digital-native and top-five legacy press online news entities from 2014 to 2015, we investigate the dynamics of intermedia agenda-setting in the context of transgender topics, both at the level of attention to transgender topics in general and at the level of attention to specific issues related to the transgender community (e.g., anti-transgender violence). Results indicate significant causal effects of digital-native coverage on legacy press coverage at the level of general attention to transgender topics. However, results also indicate that at the level of specific transgender issues, digital-native coverage drives legacy press coverage on some issues, which legacy press coverage drives digitalnative coverage on others. Implications for intermedia agenda-setting in the digital news media environment and for the future of transgender political rights movements are discussed.
\end{abstract}

Keywords transgender, intermedia, agenda-setting, digital journalism, content analysis, Granger causality

Cite as Billard, Thomas J. 2016. "Setting the Transgender Agenda: Intermedia AgendaSetting in the Digital News Environment." Politics, Groups, and Identities, in press.

doi:10.1080/21565503.2018.1532302

*The author would like to thank Ruthie Kelly for her work as a coder on this study. An earlier version of this article was presented at the May 2018 annual meeting of the International Communication Association in Prague, Czech Republic, where it received Top Student Paper award from the Political Communication Division. 


\section{Introduction}

Transgender issues have recently (and rapidly) emerged as highly salient topics of political contestation in the United States. While "LGBTQ issues" like marriage equality have predominated the public agenda for over two decades, issues of specific relevance to the transgender community have only recently registered on the national public agenda (Billard 2016; Taylor, Lewis, and HaiderMarkel 2018). Little research has addressed, however, the mechanisms by which transgender issues have been able to rise so meteorically in comparison to other, more slow-burning civil rights issues. This paper investigates one relevant factor: intermedia agenda-setting between digital-native and legacy press news entities. Whereas digital-native news entities both originated and distribute purely online (in the U.S., such entities include Buzzfeed, Huffington Post, Vice, Vox, etc.; Bennett 2016), legacy press news entities originated as major print newspapers and, for the most part, distribute both in print and online. While recent research has indicated that transgender coverage is greater in volume among digital-native news entities than among legacy press (Billard 2017), it remains unclear whether - and if so, in what ways - legacy press coverage and digital-native coverage are causally related.

In current communication theory, agenda-setting has three types. The first type, first demonstrated in McCombs and Shaw's (1972) classic "Chapel Hill study," is often referred to as "object salience" agenda-setting and refers to the effect mainstream news media have on citizens' perceptions of which issues are of political importance. The second type, often referred to as "attribute salience" agenda-setting, refers to the power of news media not only to draw citizens' attention to particular issues, but also to specific characteristics of those issues upon which they should evaluate them (McCombs and Reynolds 2009). The final type - which is the focus of this study - is intermedia agenda-setting, or the power of some media to influence the agendas of other media (McCombs and Reynolds 2009). Studies of this third type have found myriad relationships both among news media and between news media and other media. Such findings include, among others, that (1) coverage of an issue in the New York Times often causes subsequent coverage in other newspapers around the country (Mazur 1987); (2) print newspapers influence the agendas of television news broadcasts (Golan 2006; Lopez-Escobar et al. 1998); and (3) political campaign advertisements drive the issues agendas of both television broadcast news and print newspapers (Boyle 2001).

More recently, scholars of intermedia agenda-setting effects have shifted focus to how dynamics have changed in an online news environment (e.g., Ku, Kaid, and Pfau 2003; Sweetser, Golan, and Wanta 2008). While some research has suggested that intermedia agenda-setting occurs among online news sources in much the same manner as among print news sources (Lim 2011), other research has demonstrated that the emergence of new online-only media, such as blogs, have fundamentally altered agenda-setting flows (e.g., Lee, Lancendorfer, and Lee 2005; Roberts, Wanta, and Dzwo 2002; Vonbun, Kleinen-von Königslöw, and Schoenbach 2016). For example, Messner and Distaso (2008) found that blogs and print newspapers have reciprocal intermedia agenda-setting effects, while Meraz $(2009,2011)$ found that traditional media largely fail to set blog agendas, though blogs succeed in setting traditional media agendas. The introduction of social media, such as Facebook and Twitter, has further transformed intermedia agenda-setting dynamics, as social media content (to varying degrees and on certain issues) engages in reciprocal agenda-setting with traditional news media (Groshek and Clough Groshek 2013; Neuman et al. 2014). Although most of this research has compared the agendas of traditional news media to those of blogs or social media, Austrian scholars Vonbun, Kleinen-von Königslöw, and Schoenbach (2016: 1065) recently found that, in the broader news media ecology, it is mainstream online news media that "dominate intermedia agenda-setting."

These intermedia agenda-setting effects occur for a number of reasons, with the primary reason being competition for shares of the informational market. That is, in order to ensure that they are not missing coverage of topics or events being offered by their economic competitors, which 
might result in a loss of audience, news entities monitor their competitors' content and adjust their own coverage accordingly (Lim 2006). At the same time, as Donsbach (2004) has argued, seeing coverage of a topic or event by a competitor legitimates the subject matter as newsworthy to news entities that had not covered it, further incentivizing them to follow suit. Of course, this behavior is not an innovation of digital journalism; Tuchman (1978) documented such practices in her landmark Making News, observing night editors receiving first editions of competitors' papers to rewrite their own papers for the morning edition. However, the use of data analytics in the editorial practices of online news making have centered this kind of surveillance of competitors, as well as of one's own website visitors, in the agenda-setting process (Ragas, Tran, and Martin 2014; Tandoc 2014). Considering particularly that, according to Pew Research Center's (2015: 15, 30) State of the News Media report, the top-10 digital-native news sites receive an average of 37,274 monthly unique visitors, while the top-10 legacy press websites receive an average of 34,541 , legacy press news entities are likely to look to digital-native entities' content innovations in the quest to recover their share of a shrinking news audience.

Existing research on intermedia agenda-setting in the online environment, however, has thus far failed to compare the agendas of traditional news media to media in the rapidly proliferating category of mainstream digital-native news. Additionally, these studies have considered issues of general, mainstream interest such as legislative and administrative politics, candidates, and elections (e.g., Lee, Lancendorfer, and Lee 2005; Meraz 2009, 2011; Sweetser, Golan, and Wanta 2008; Vonbun, Kleinen-von Königslöw, and Schoenbach, 2016). The dynamics of agenda-setting regarding issues of less certain political significance - like previously marginal topics relating to social out-groupsare likely to differ. As Hallin (1986), among others, has demonstrated, traditional news media are hesitant to dedicate attention to marginal topics without external pressures - and coverage among digital news entities with which traditional media must compete might serve as requisite pressure.

Transgender topics may serve as one key example of this. As Billard (2016) argued - drawing on Hallin (1986) - legacy press news coverage serves as a means of legitimating transgender issues and identities, and it is through not only increases in coverage amount but also changes in coverage quality that transgender issues are legitimated in the political realm. Between 2003 and 2013 both the amount of coverage of and the amount legitimacy conferred to transgender issues in American legacy press increased significantly, thus bringing transgender issues into the realm of legitimate political controversy (Billard, 2016). However, Billard's (2017) recent study of digital-native and legacy press online news coverage of transgender topics offered early evidence that transgender issues are conferred more legitimacy among digital-native entities than among legacy press, thus suggesting that potentially politically-consequential differences persist between them. Thus, if intermedia agenda-setting dynamics exist among digital-native and legacy press online news, this may have significant effects on the legitimation of transgender topics in American politics. It is against this theoretical background that we pose the following research questions:

RQ1: To what extent do the agendas of legacy press and digital-native online news entities differ at both the levels of (a) general attention and (b) specific topical focus in the context of transgender issues?

RQ2: (a) How do the agendas of both types of online news entities relate to one another and (b) are intermedia agenda-setting dynamics involved in their relationship?

\section{Method}

To answer these research questions, we conducted a mixed-methods content analysis of articles focusing on transgender issues from a sample of legacy press and digital-native online news sources. 
We drew our sample from Media Cloud, an online-news aggregation service co-run by the Center for Civic Media at MIT and the Berkman Center for Internet \& Society at Harvard University. The sample consisted of the top five legacy newspaper websites and top five digital-native news websites (as measured by number of unique visitors) identified in the Pew Research Center (2015) State of the News Media report. Only U.S.-based purveyors of general news (i.e., not exclusively specialized news such as sport, entertainment, technology, etc.) were considered. Moreover, news websites that operate exclusively as blogs (e.g., Gawker) were excluded. As such, the sample included articles from the websites of legacy press entities USA Today, the New York Times, the Washington Post, the Los Angeles Times, and the San Francisco Chronicle (SFGate.com), and digital-native entities the Huffington Post, Buzzfeed, Slate, Vice, and Vox.

In order to capture news coverage during the time of greatest increase in mainstream transgender visibility, both in politics (e.g., the referendum on Houston's Equal Rights Ordinance) and popular culture (e.g., Laverne Cox on the cover of Time magazine, Caitlyn Jenner coming out), we selected a sampling frame from 1 January 2014 to 31 December 2015. Articles were identified through a keyword search that filtered for stories containing any of the keywords: "transgender," "transsexual," "transexual," and "transgendered." Articles were excluded that did not include one of these keywords (or their abbreviation "trans") more than once outside of the phrase "lesbian, gay, bisexual, and transgender" or one of its variants. This sampling frame yielded a total of 3,481 articles, from which $700(20 \%)$ were randomly sampled for coding.

Two political communication scholars with research expertise in media representations of gender worked as coders for this study. Coding was conducted at an article level of analysis and the following measures were coded: (a) news source (e.g., New York Times, Buzzfeed, etc.); (b) date of publication; and (c) topic or issue discussed in the story. Because, in contrast to past agenda-setting research (e.g., Lee, Lancendorfer, and Lee 2005), we assessed all topics pertaining to transgender individuals and issues, we did not have an a priori list of topics that we sampled and coded for. Thus, coding story topics required an iterative process of content analysis in which story topic codes were generated using a small subsample and subsequently applied to the general study sample. Following Cho and Lee (2014), we took an inductive approach to qualitative content analysis using the first 200 news articles from our sample. Fifty of these subsample articles were analyzed at the story level and submitted to an initial round of open coding, through which we established a core set of codes. We then coded the remainder of the 200-article subsample data with these preliminary codes. Where these codes were inadequate, additional codes were created and previously coded data were reevaluated. This resulted in a total of 10 codes in addition to the miscellaneous "other" category $(n=9)$ : anti-transgender violence $(n=11)$, Caitlyn Jenner $(n=33)$, coming out/outing $(n=15)$, discrimination $(n=25)$, legislation and litigation $(n=17)$, medical issues/healthcare $(n=10)$, nonbinary identities/third gender $(n=7)$, transgender representation in media and entertainment $(n=36)$, transgender children and education $(n=22)$, and transgender military service $(n=15)$. All 200 subsample stories were coded based on the consensus of both coders.

Using the codes developed through this inductive process, the remaining 500 articles in the sample were coded following Krippendorff's (2004) guidelines for quantitative content analysis. Articles were coded at the story level and each article could only be coded as having one story topic. Where multiple topics were addressed in a single article, coders identified the topic that was given greater prominence, where prominence was determined by the number of paragraphs relevant to each topic. Intercoder reliability was assessed by selecting a 100-article (20\%) subsample of the 500 remaining articles for comparison between both coders; acceptably high intercoder reliability for story topic was achieved, percent agreement $=89 \%$, Krippendorff's $\alpha=.87 .{ }^{1}$ Disagreements were resolved by

\footnotetext{
${ }^{1}$ For story topics with five or more instances in the 100 -article intercoder reliability subsample (i.e., 7 of the 11 topic codes), percent agreement ranged from $80 \%$ to $100 \%$. Percent agreement for the four topic codes with fewer
} 
consensus of the coders.

To test for intermedia agenda-setting effects between digital-native and legacy press news media, we followed past studies (e.g., Groshek and Clough Groshek 2013; Meraz 2011; Neuman et al. 2014) in conducting a series of Granger (1969) causality tests, which offer a means of testing time-ordered relationships between parallel time series; specifically, a statistically significant result indicates that past values of one time series predict future values of the other. As Groshek and Clough Groshek (2013: 19) remarked, "this technique can statistically determine when topic salience in one media agenda precedes and predictively explains topic salience in another media agenda." Of course, such statistical relationships do not confirm real-world causality, but they nonetheless offer an indication of time-ordered effects such that one time series is said to "Granger cause" the other (Freeman, 1983).

In order to avoid excesses of daily non-value data points for our analyses, we collapsed the coded dates into weeklong intervals beginning with the week of 1 January 2014. This resulted in 105 weekly observations. While this necessarily precludes the possibility of detecting intermedia agendasetting effects that occur within a single week, past research by Roberts, Wanta, and Dzwo (2002) has indicated that agenda-setting between legacy press and online discourse is most prominent at a lag of 7 days. Moreover, given that fewer than one article per day on average would be published from the 700-article sample over the two-year timeframe, we would likely observe few, if any, effects analyzing intermedia agenda-setting at daily intervals.

For Granger causality tests to be successfully conducted, three conditions must be met. First, Granger tests require a minimum of 40 unique observations (Poole, McPhee, and Canary 2002). Since we have 105 unique observations, our data meet this criterion. Second, Granger tests require that vectors achieve "stationarity," or consistency in statistical parameters (e.g., mean, variance, autocorrelation) over time (Cryer and Chan, 2008). A series of augmented Dickey-Fuller tests confirmed the stationarity of our vectors. Finally, appropriate time lags for the Granger causality tests must be selected via statistical means (Enders, 1995). In the present study, the Akaike information criterion (AIC) and Schwarz's Bayesian information criterion (SBIC) were calculated for each time series to identify the appropriate lags; when the AIC and SBIC conflicted, sequential $F$-tests were run to confirm which lag value to employ (Weber 2001).

Having established these three conditions were met, we then conducted the Granger causality tests, which required a series of test pairs - one test assessing the predictive power of the first time series on the second and another test assessing the reverse. $F$-statistics were calculated for each test; a significant $F$-statistic indicated a significant causal relationship in the direction of the model. If neither test in the pair was significant then there were no Granger causal relationships, whereas if both tests were significant then there was "mutual reciprocal Granger causation" (Neuman et al. 2014: 204).

\section{Results}

Of the 700 articles sampled for this study, significantly more came from digital-native news entities $(n=420)$ than from legacy press online news sources $(n=280), \chi^{2}(1, N=700)=27.6, p<$ .0001 ; this is perfectly reflective of the overall population of articles from which we sampled $(2,121$ articles from digital-native vs. 1,360 articles from legacy press), $\chi^{2}(1, N=3,481)=166.37, p<$ .0001. However, despite this clear difference in overall coverage frequency, we observed no significant differences in coverage dedicated to individual topics (as a percentage of all coverage) between legacy press and digital-native online news. That is, the percentage of digital-native stories dedicated to a

than five instances would be uninterpretable and were thus not calculated. 
specific topic was never statistically significantly different from the percentage of legacy-press stories dedicated to the same topic (see Table 1). Moreover, the results of a Kendall rank correlation test revealed a significant correlation in topic ranks between the two types of news entities, $\tau=0.75, p$ $<.001$, indicating that relative attention levels to each topic were similar across both entity types.

Table 1: Story Topic Distribution by News Source Type

\begin{tabular}{lll} 
Topic & $\begin{array}{l}\% \text { of Digital-Native } \\
\text { Articles }(n)\end{array}$ & $\begin{array}{l}\% \text { of Legacy Press } \\
\text { Articles }(n)\end{array}$ \\
\hline $\begin{array}{l}\text { Discrimination } \\
\text { Transgender Representation in Media and Enter- }\end{array}$ & $17.4 \%(75)$ & $18.6 \%(52)$ \\
tainment & $17.1 \%(72)$ & $12.5 \%(35)$ \\
Caitlyn Jenner & $15.0 \%(63)$ & $13.9 \%(39)$ \\
Other & $10.2 \%(43)$ & $13.6 \%(38)$ \\
Anti-transgender Violence & $7.9 \%(33)$ & $9.6 \%(27)$ \\
Transgender Children and Education & $7.1 \%(30)$ & $8.9 \%(25)$ \\
Legislation and Litigation & $6.9 \%(29)$ & $5.7 \%(16)$ \\
Medical Issues/Healthcare & $5.2 \%(22)$ & $2.5 \%(7)$ \\
Transgender Military Service & $4.5 \%(19)$ & $5.0 \%(14)$ \\
Coming Out/Outing & $4.3 \%(18)$ & $6.4 \%(18)$ \\
Nonbinary Identities/Third Gender & $4.3 \%(18)$ & $3.2 \%(9)$ \\
Total & $99.9 \%(420)$ & $99.9 \%(280)$ \\
\hline Note: Totals do not sum to 100\% due to rounding. & \\
\hline
\end{tabular}

Looking at the relationship between digital-native and legacy press coverage at the level of general attention to transgender topics, we observed a significant correlation between their two agendas, $r(103)=0.59, p<.0001$. In other words, overall trends in coverage frequency correlated significantly between both news outlet types such that when one outlet type increased or decreased its coverage amount, so did the other. However, results of the Granger causality test revealed a significant influence of digital-native news coverage on legacy press coverage at the level of general coverage of transgender issues such that changes in digital-native coverage "Granger caused" subsequent changes in legacy press coverage (see Table 2). Figure 1 presents a plot of these trends. Thus, these results indicate that the overall amount of attention legacy newspaper websites dedicated to transgender topics was an outcome of intermedia agenda-setting influence from digital-native news sites.

Shifting to the relationships between digital-native and legacy press coverage at the level of specific transgender issues, only for the issue of anti-transgender violence did digital-native and legacy press agendas correlate significantly, $r(103)=0.29, p=.003$; for no other issue did the agendas of the two news source types correlate (see Table 2). Yet, while their individual issue agendas did not correlate cotemporally, the results of several Granger causality test were significant, indicating that digital-native news coverage and legacy press coverage influenced one another on a variety of issues. Specifically, our results indicated that digital-native coverage "Granger caused" subsequent legacy press coverage of issues pertaining to anti-transgender violence, as well as transgender children and education, while legacy press drove later digital-native coverage of nonbinary identities/third gender issues (see Table 2). Interestingly, however, the results of the Granger causality test on coverage of discrimination issues suggested bidirectional causality between legacy press and digital-native entities. That is, legacy press and digital-native coverage of discrimination issues had a mutual causal relationship such that past values of both time series predicted future values of the other. Taken together, these results indicate that digital-native coverage exerts an intermedia agendasetting influence on legacy press coverage for some issues, while legacy press coverage exerts an 
Table 2: Relationships Between Digital-Native and Legacy Press News Media Time Series Correlation between Granger Causality Test $\mathrm{DN}$ and LP

\begin{tabular}{|c|c|c|c|c|}
\hline Variable & $r(103)$ & lags & $\mathrm{F}$ & $\mathrm{p}$ \\
\hline Overall Coverage & $0.59^{* * *}$ & & & \\
\hline $\mathrm{DN} \rightarrow \mathrm{LP}^{*}$ & & 1 & 6.43 & .01 \\
\hline $\mathrm{LP} \rightarrow \mathrm{DN}$ & & 1 & 2.86 & .09 \\
\hline Anti-transgender Violence & $0.29^{* *}$ & & & \\
\hline $\mathrm{DN} \rightarrow \mathrm{LP}^{* *}$ & & 1 & 9.68 & .002 \\
\hline $\mathrm{LP} \rightarrow \mathrm{DN}$ & & 1 & 2.08 & .15 \\
\hline Caitlyn Jenner & -0.01 & & & \\
\hline $\mathrm{DN} \rightarrow \mathrm{LP}$ & & 1 & 1.06 & .31 \\
\hline $\mathrm{LP} \rightarrow \mathrm{DN}$ & & 1 & 0.20 & .65 \\
\hline Coming Out/Outing & -0.01 & & & \\
\hline $\mathrm{DN} \rightarrow \mathrm{LP}$ & & 1 & 0.25 & .62 \\
\hline $\mathrm{LP} \rightarrow \mathrm{DN}$ & & 1 & 0.31 & .57 \\
\hline Discrimination & 0.19 & & & \\
\hline $\mathrm{DN} \rightarrow \mathrm{LP}^{*}$ & & 4 & 2.83 & .03 \\
\hline $\mathrm{LP} \rightarrow \mathrm{DN}^{* *}$ & & 4 & 4.04 & .005 \\
\hline Legislation and Litigation & -0.02 & & & \\
\hline $\mathrm{DN} \rightarrow \mathrm{LP}$ & & 1 & 0.12 & .73 \\
\hline $\mathrm{LP} \rightarrow \mathrm{DN}$ & & 1 & 0.11 & .75 \\
\hline Medical Issues/Healthcare & 0.04 & & & \\
\hline $\mathrm{DN} \rightarrow \mathrm{LP}$ & & 1 & 1.64 & .20 \\
\hline $\mathrm{LP} \rightarrow \mathrm{DN}$ & & 1 & 0.15 & .71 \\
\hline Nonbinary Identities/Third Gender & 0.04 & & & \\
\hline $\mathrm{DN} \rightarrow \mathrm{LP}$ & & 1 & 0.21 & .65 \\
\hline $\mathrm{LP} \rightarrow \mathrm{DN}^{* *}$ & & 1 & 8.53 & .004 \\
\hline $\begin{array}{l}\text { Transgender Representation in Media and En- } \\
\text { tertainment }\end{array}$ & 0.18 & & & \\
\hline $\mathrm{DN} \rightarrow \mathrm{LP}$ & & 1 & 0.61 & .44 \\
\hline $\mathrm{LP} \rightarrow \mathrm{DN}$ & & 1 & 0.29 & .60 \\
\hline Transgender Children and Education & -0.04 & & & \\
\hline $\mathrm{DN} \rightarrow \mathrm{LP}^{* * *}$ & & 1 & 16.02 & .0001 \\
\hline $\mathrm{LP} \rightarrow \mathrm{DN}$ & & 1 & 0.59 & .45 \\
\hline Transgender Military Service & -0.03 & & & \\
\hline $\mathrm{DN} \rightarrow \mathrm{LP}$ & & 1 & 0.07 & .80 \\
\hline $\mathrm{LP} \rightarrow \mathrm{DN}$ & & 1 & 0.10 & .76 \\
\hline
\end{tabular}




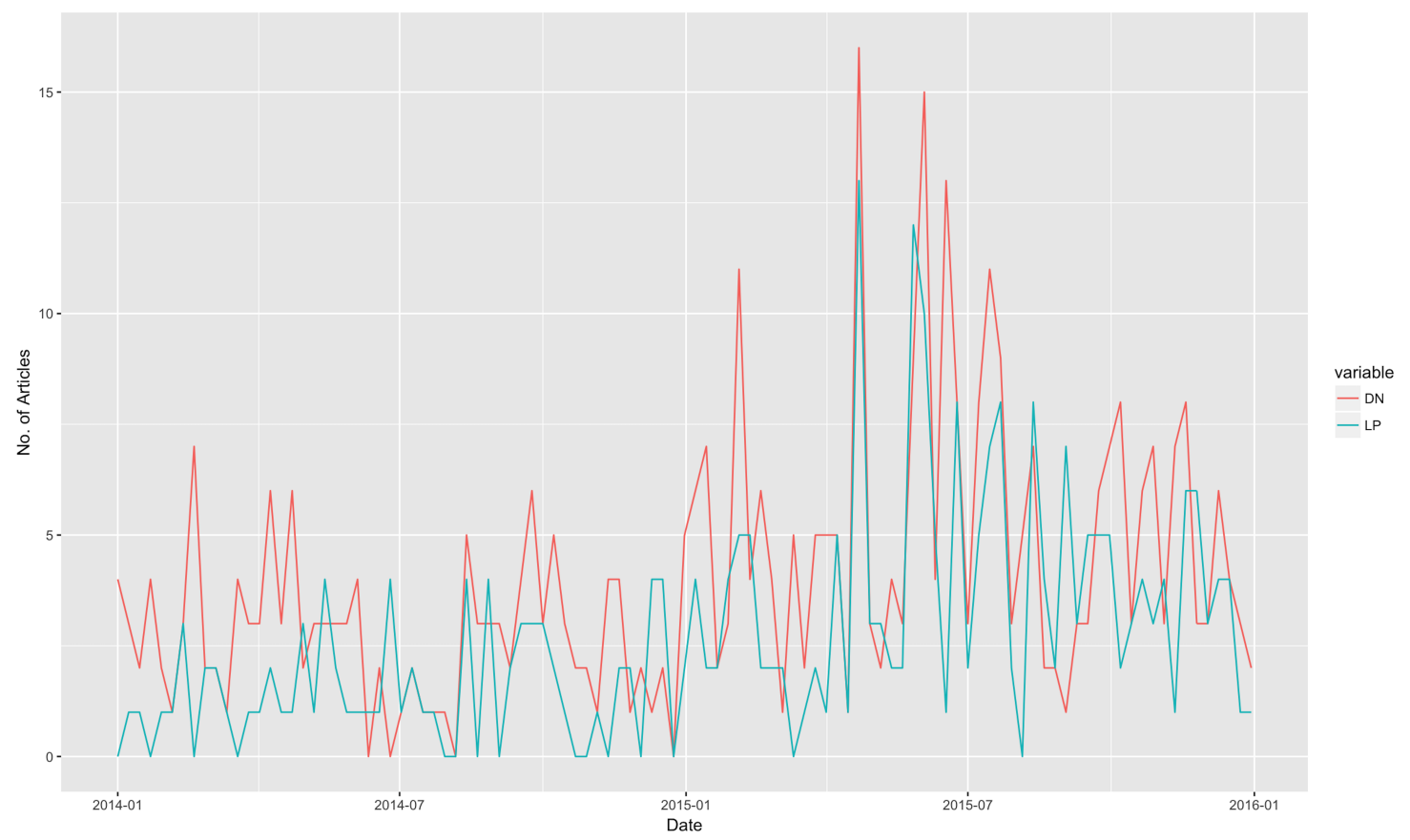

Figure 1: Total weekly coverage over time by news source type $(\mathrm{D} n=$ Digital-Native, LP $=$ Legacy Press).

intermedia agenda-setting influence on digital-native coverage for others.

\section{Discussion}

This study investigated the dynamics of intermedia agenda-setting between legacy press and digitalnative online news sources in the context of transgender topics. Beyond illuminating how intermedia agenda-setting effects have changed in the digital news environment-particularly with the emergence of mainstream digital-native news entities (Bennett 2016) - this study offers insight into one mechanism by which transgender issues have so rapidly achieved salience in mainstream news media. Yet this study also contributes to our understanding of how digital-native yet still mainstream online news sources (as opposed to blogs, social media, etc.) fit into the collective agenda-building process of the contemporary news media environment, illustrating the particular role played by digital-native news entities in driving attention to marginal social issues among legacy press entities.

Overall, digital-native news entities dedicated more coverage to transgender topics over the twoyear span from 2014 to 2015 than did legacy press online news sources. As a proportion of their respective coverage, however, the two source types did not, in the aggregate, differ significantly in their amount of focus on specific issues. Looking at the dynamics of intermedia agenda-setting between the two types of online news, we found that changes in the amount of digital-native coverage drove subsequent changes in legacy press coverage at the level of general attention to transgender topics. On individual transgender issues, however, digital-native coverage drove changes in legacy press coverage on several issues, while legacy press coverage drove digital-native coverage on others. It is nonetheless noteworthy that digital-native coverage drove legacy press coverage on a greater 
number of issues, which suggests that, on the whole, changes in legacy press coverage were a product of increases in digital-native attention. Taken together, these results suggest that coverage among digital-native online news entities is a driving force in increasing attention to transgender concerns among legacy press online news entities, although legacy press retains some (limited) power in setting specific issue agendas, and similar dynamics may be identified in other contexts in future work.

Questions of why we observe these results are harder to answer, but past literature offers some potential explanations. In some respects, it seems almost obvious that emerging agenda items pertaining to a marginalized population would be more prevalent in digital-native news, as these entities are more closely linked to the agendas of social media (Bennett 2016), which "spend a lot more time discussing social issues such as birth control, abortion, and same-sex marriage ? than the traditional media" (Neuman et al. 2014: 210). Additionally, the economic and organizational logics of news media allow new issues to arise in digital-native coverage in ways less possible in legacy press. Digital news distribution allows for the specialized targeting of narrower audiences (Klinenberg 2005), which online news entities - both digital-native and legacy press - do in order to maximize visitor counts because they cannot "meaningfully charge for content" (Freedman 2010: 45). As a result, topics unlikely to emerge in print newspapers receive coverage online, as editors use web metrics to determine "which topics, headlines, and story assets [are] more likely to generate traffic" (Tandoc 2014: 571).

Though both digital-native and legacy press news entities use web metrics in their gatekeeping practices, key differences in how those entities use metrics persist. As Scacco, Curry, and Stroud (2016) documented, digital-native news entities routinize individual journalists' integration of metrics into their work practices more extensively, which legacy press entities can less easily do due to their larger size. This reliance on metrics is fundamentally tied to discussions of "return on investment" among digital-native entities, which is less (openly) considered by legacy press. Moreover, legacy press entities often maintain a newsroom culture that centers the print product, even online, such that "projects sometimes have to be tied to a print story to get first class treatment" (Scacco, Curry, and Stroud 2016).

Thus, digital-native entities are more likely to produce a wider variety of coverage to maximize audience visits and to do so on the bases of web metrics that point them to (perhaps unexpectedly) high-traffic content. However, with digital-native entities reporting on issues not discussed by legacy press, legacy press news sites lose some share of the informational market to their digital-native competitors, driving them to increase their coverage of those issues and thus remain competitive. As Tandoc (2014) noted, editors' perceptions both of their audiences' viewing preferences and of their competitors' offerings lead them to alter their gatekeeping decisions (see also Scacco, Curry, and Stroud 2016).

In the context of transgender topics, we might imagine these mechanisms underlie digital-native coverage's influence on legacy press coverage. As Hallin (1986) noted, groups and topics are afforded legitimacy by their presence in legacy press' sphere of legitimate controversy. Thus, as digital-native coverage drives increases in legacy press coverage, the implication is that digital-native coverage allows transgender topics an avenue from the margins into broader public debate (Billard 2016)one path (of many) to mainstream political legitimacy. As such, these dynamics may explain, in part, the rapid emergence of transgender topics on the national political agenda (Taylor, Lewis, and Haider-Markel 2018). Moreover, as McCombs has argued over his long career of agenda-setting research, an increased salience in news media affords topics increased perceived significance in the minds of citizens (McCombs and Reynolds 2009). This leaves us, then, with further questions about the consequences of digital-native coverage in terms of its indirect influence (via influence on legacy press) both on the general public and on political elites, whose discourses and agendas are shaped, in part, by those of legacy press (Entman 2003). 
Additional avenues for further research remain open, as well. First, further studies could seek to replicate these findings in contexts of other issues and identities - particularly those lacking mainstream legitimacy. Second, future studies could investigate differences in the specific content of articles (e.g., sourcing patterns, etc.) between legacy press and digital-native online news entities, rather than overall topical focus. Third, future research could interrogate the mechanisms that drive both differences in news coverage of these topics and the intermedia agenda-setting dynamics observed. Finally, future research could investigate how the effects of digital-native and legacy press online news content on knowledge, attitudes, and opinions differ to illuminate the broader consequences of the differences observed in this study. 


\section{References}

Bennett, W. Lance. 2016. News: The Politics of Illusion. Chicago: University of Chicago Press.

Billard, Thomas J. 2016. "Writing in the Margins: Mainstream News Media Representations of Transgenderism." International Journal of Communication 10:4193-4218.

Billard, Thomas J. 2017. "Digital Transitions: Investigating Content Differences in Legacy Press and Digital-Native Online News Coverage of Transgender Topics." Paper presented at the annual meeting of the International Communication Association, San Diego, California, May 25-29.

Boyle, Thomas P. 2001. "Intermedia Agenda Setting in the 1996 Presidential Election." Journalism \& Mass Communication Quarterly 78 (1):26-44.

Cho, Ji Young, and Eun-Hee Lee. 2014. "Reducing Confusion about Grounded Theory and Qualitative Content Analysis." Qualitative Report 19.

Cryer, Jonathan D. and Kung-Sik Chan. 2008. Time Series Analysis. New York: Springer-Verlag.

Donsbach, Wolfgang. 2004. "Psychology of News Decisions: Factors Behind Journalists' Professional Behavior." Journalism 5 (2), 131-157.

Enders, Walter. 1995. Applied Econometric Time Series. New York: Wiley.

Entman, Robert M. 2003. "Cascading Activation: Contesting the White House's Frame after 9/11." Political Communication 20 (4):415-432.

Freedman, Des. 2010. "The Political Economy of the 'New' News Environment." In New Media, Old News, edited by Natalie Fenton, 35-50. London: Sage.

Freeman, John R. 1983. "Granger Causality and the Times Series Analysis of Political Relationships." American Journal of Political Science 27 (2):327-358.

Golan, Guy. 2006. "Inter-media Agenda Setting and Global News Coverage." Journalism Studies 7 (2):323-333

Granger, C.W.J. 1969. "Investigating Causal Relations by Econometric Models and Cross-spectral Methods." Econometrica 37 (3):424-438.

Groshek, Jacob, and Megan Clough Groshek. 2013. "Agenda Trending: Reciprocity and the Predictive Capacity of Social Networking Sites in Intermedia Agenda Setting across Topics over Time." Media and Communication 1 (1):15-27.

Hallin, Daniel C. 1986. The "Uncensored War": The Media and Vietnam. Berkeley: University of California Press.

Klinenberg, Eric. 2005. "Convergence: News Production in a Digital Age." Annals of the American Academy of Political and Social Science 597:48-64.

Krippendorff, Klaus. 2004. Content Analysis: An Introduction to its Methodology. Newbury Park: Sage.

Ku, GyoTae, Lynda Lee Kaid, and Michael Pfau. 2003. "The Impact of Web Site Campaigning on Traditional News Media and Public Information Processing." Journalism $\&$ Mass Communication Quarterly 80 (3):528-547.

Lee, Byoungkwan, Karen M. Lancendorfer, and Ki Jung Lee. 2005. "Agenda-Setting and the Internet." Asian Journal of Communication 15 (1):57-71.

Lim, Jeongsub. 2006. "A Cross-Lagged Analysis of Agenda Setting among Online News Media." Journalism 83 Mass Communication Quarterly 83 (2):298-312.

Lim, Jeongsub. 2011. "First-Level and Second-Level Intermedia Agenda-Setting Among Major News Websites." Asian Journal of Communication 21 (2):167-185.

Lopez-Escobar, Esteban, Juan Pablo Llamas, Maxwell McCombs, and Frederico Rey Lennon. 1998. "Two Levels of Agenda Setting Among Advertising and News in the 1995 Spanish Elections." Political Communication 15 (2):225-238.

Mazur, Allan. 1987. "Putting Radon on the Public Risk Agenda." Science, Technology and Human Values 12:86-93. 
McCombs, Maxwell and Amy Reynolds. 2009. "How the News Shapes our Civic Agenda." In Media Effects: Advances in Theory and Research, edited by Jennings Bryant and Mary Beth Oliver, 1-16. New York: Routledge.

McCombs, Maxwell and Donald Shaw. 1972. "The Agenda-Setting Function of Mass Media." Public Opinions Quarterly 36 (2):176-187.

Meraz, Sharon. 2009. "Is There an Elite Hold? Traditional Media to Social Media Agenda Setting Influence in Blog Networks." Journal of Computer-Mediated Communication 14 (3):682-707.

Meraz, Sharon. 2011. "Using Time Series Analysis to Measure Intermedia Agenda-setting Influence in Traditional Media and Political Blog Networks." Journalism \&s Mass Communication Quarterly 88 (1):176-194.

Messner, Marcus, and Marcia Watson Distaso. 2008. "The Source Cycle: How Traditional Media and Weblogs Use Each Other as Sources." Journalism Studies 9 (3):447-463.

Neuman, W. Russell, Lauren Guggenheim, S. Mo Jang, and Soo Young Bae. 2014. "The Dynamics of Public Attention: Agenda-Setting Theory Meets Big Data." Journal of Communication 64 (2):193-214.

Pew Research Center. 2015. "State of the News Media 2015." Washington: Pew Research Center.

Poole, Marshall Scott, Robert D. McPhee, and Daniel J. Canary. 2002. "Hypothesis Testing and Modeling Perspectives on Inquiry." In Handbook of Interpersonal Communication, edited by Mark Knapp and John Daley, 23-72. Thousand Oaks: Sage.

Roberts, Marilyn, Wayne Wanta, and Tzong-Horng Dzwo. 2002. "Agenda Setting and Issue Salience Online." Communication Research 29 (4):452-465.

Scacco, Joshua, Alexander L. Curry, and Natalie J. Stroud. 2016. "Digital Divisions: Organizational Gatekeeping Practices in the Context of Online News." \#ISOJ 6 (1).

Sweetser, Kaye D., Guy Golan, and Wayne Wanta. 2008. "Intermedia Agenda Setting in Television, Advertising, and Blogs During the 2004 Election." Mass Communication 85 Society 11 (2):197216.

Tandoc, Edson C. 2014. "Journalism is Twerking? How Web Analytics is Changing the Process of Gatekeeping." New Media 83 Society 16 (4):559-575.

Taylor, Jami Kathleen, Daniel C. Lewis, and Donald P. Haider-Markel. 2018. The Remarkable Rise of Transgender Rights. Ann Arbor: University of Michigan Press.

Tuchman, Gaye. 1978. Making News: A Study in the Construction of Reality. New York: Free Press.

Vonbun, Ramona, Katharina Kleinen-von Königslöw, and Klaus Schoenbach. 2016. "Intermedia Agenda-Setting in a Multimedia News Environment." Journalism 17 (8):1054-1073.

Weber, Christian E. 2001. "F-tests for Lag Length Selection in Augmented Dickey-Fuller Regressions." Applied Economics Letters 8 (7):455-458. 